\title{
A SIMPLE METHOD FOR DETERMINATION AND CHARACTERIZATION OF IMIDAZOLINONE HERBICIDE (IMAZAPYR/IMAZAPIC) RESIDUES IN CLEARFIELD ${ }^{\circledR}$ RICE SOIL
}

\author{
MAHYOUB, I. B. ${ }^{1}$ - FATHIAH, M. Z. ${ }^{2 *}$ - MUHAMAD, S. M. ${ }^{1}-$ MOHAMED, K. A. ${ }^{2}-$ JODEH, S. W. ${ }^{3}-$ \\ MONZIR, S. A. ${ }^{4}$ \\ ${ }^{I}$ Institute of Biological Sciences, Faculty of Science, University of Malaya \\ 50603 Kuala Lumpur, Malaysia \\ ${ }^{2}$ Department of Chemical Engineering, Faculty of Engineering, University of Malaya \\ 50603 Kuala Lumpur, Malaysia \\ ${ }^{3}$ Department of Chemistry, Faculty of Science, An-Najah National University \\ P. O. Box 7, Nablus, Palestine \\ (e-mail: sjodeh@najah.edu; fax:+97-092-345-982) \\ ${ }^{4}$ Department of Chemistry, Islamic University of Gaza, Gaza, Palestine \\ (e-mail:mlatif@iugaza.edu.ps) \\ *Corresponding author \\ e-mail:fathiahmz@um.edu.my; tel: +60-379-676-879; mobile:+60-196-090-504) \\ (Received 24 $4^{\text {th }}$ May 2017; accepted $2^{\text {nd }}$ Aug 2017)
}

\begin{abstract}
A study was conducted to evaluate residues of imidazolinone (IMI) in soil. Samples were taken from three Clearfield ${ }^{\circledR}$ rice fields as IMI which have been used for six years. IMI herbicides (imazapic/imazapyr) were widely used in Clearfield ${ }^{\mathbb{B}}$ rice soils. To date, few studies are available on the residues of these herbicides, especially in the context of Malaysian soil. Therefore, for this purpose, high performance liquid chromatography (HPLC) with UV detection was performed using a Zorbax stable bond $\mathrm{C}_{18}(4.6 \times 250 \mathrm{~mm}, 5 \mu \mathrm{m})$ column, with two mobile phases. The average percentage recovery for imazapyr and imazapic varied from $76 \%-107 \%$ and $71-77 \%$, with $0.1-5 \mu \mathrm{g} / \mathrm{ml}$ fortification level, respectively. The limit of detection (LOD) and limit of quantification (LOQ) were found to be 1.05 and 4.09 for imazapic and 0.171 and $0.511 \mu \mathrm{g} / \mathrm{ml}$ for imazapyr respectively, in the top $15 \mathrm{~cm}$. In the extracted soil sample, it was $0.19 \mu \mathrm{g} / \mathrm{ml}$ for imazapic and $0.04 \mu \mathrm{g} / \mathrm{ml}$ for imazapyr, respectively. Based on this study, a pre-harvest period of 40-60 day is suggested for rice crops after IMI application.
\end{abstract}

Keywords: recovery, acetonitrile, Zorbax stable bond $C_{18}$, HPLC, terminal residues, Clearfield ${ }^{\circledR}$ rice

\section{Introduction}

Weedy rice (WR) is a notorious weed associated with rice paddy crops. WR in Malaysia (locally known as Padi Angin) was first observed and reported in 1988 (Watanabe et al., 1996). WR also always acted as dominant competitor in terms of interand intra- varietal competitions among rice species (Baki and Shakirin, 2010). The application of pesticides in the agricultural system becomes unavoidable in the present day, as it increases production and decreases yield loss caused by pests (Schreiber et al., 2017). In 2010, the introduction of a new type of imidazolinone herbicide (IMI) known as OnDuty ${ }^{\circledR}$ with its main ingredient being imazapyr/imazapic, was used in Malaysia's agricultural system (Azmi et al., 2011). Because sometimes mixing two or more herbicides into one spray solution can offer producers multiple benefits (Fish et al., 
2015). This resulted in an overnight success in rice cultivation in terms of yields and WR control. It also helps control a broad spectrum of weeds, encompassing grasses, and cyperaceous and broad-leaved plants, and those that WR are closely associated to (Neto et al., 2017).

IMI inhibits the enzyme function in the plant known as acetohydroxyacid synthase (AHAS) (Bailey and Wilcut, 2003), which starves the plant and lead to its death. Upon the introduction of IMI - resistant cultivated rice $\left(\right.$ Clearfield $\left.{ }^{\circledR}\right)$, most difficulties faced by farmers that are related to WR have almost been completely solved. OnDuty ${ }^{\circledR}$ herbicide formulation containing imazapyr is a generic name for [2-(4-isopropyl- 4methyl-5-oxo-2-imidazoline-2-yl) nicotinic acid]; trade names of Arsenal and Chopper), while imazapic is the generic name of [2-(4,5dihydro-4-methy-4-(1-methylethyl)-5-oxo1Himidazol-2-yl)5-methyl-3-pyridinecarboxylic acid]; trade names of Cadre and Plateau (Azmi et al., 2012). Both are widely used in WR, and its efficiency has been proven. IMI is relatively persistent in soil, with half-lives ranging from $30-150$ days (Kemmerich et al., 2015). Shorter half-lives of imazapyr (34-65 days) detected in forest soils (Michael and Neary, 1993).

IMI have two enantiomers (Krieger, 2001) derived from the chiral center, which consists of imazapyr, imazapic, imazaquin, imazamox, imazethapyr and imazamethabenz-methyl, as per Table 1. IMI detection and research separation from water and soil are limited compared to other types of herbicides due to the low application rate (100-200g/ha) and co-extraction of other substances that interfere with chromatogram and low rates of application (Ramezani et al., 2009; Andreu and Picó, 2004). However, In the last decade, diverse studies were done on these types of herbicides to assess the risk assessment to the environments as water and soil (Silva et al., 2009; Anastassiades et al., 2003; Andreu and Picó, 2004; Börjesson et al., 2004; Bajrai et al., 2017). Also, the massive use of IMI herbicides might have contributed to the increase in resistant weedy rice, also, in most cases, herbicides-resistant weeds go undetected until they represent about 30\% of the total population (Burgos et al., 2014). Many reports showed the imidazolinone carryover affected many non-rice crops in rotational systems (Alister and Kogan, 2005).

Studies on how much of these herbicides run-off into soil and water are important due to their potentially harmful influence on the environment (Schreiber et al., 2017). Developing methods for extraction in water and soil are very important, because some studies revealed that the residues of these herbicides remain present in Swedish soil after 8 hours (Börjesson et al., 2004). Herbicidal residue is defined as the remaining herbicides on or in the soil after its application in agricultural soil. Its persistence in soil sometimes causes injuries in the next crop (Assalin et al., 2014). Most previous studies on this type of herbicides used alkaline/acidified water, methanol, acetonitrile, and diverse techniques for the extraction process (Helling and Doherty, 1995; Ramezani et al., 2009). The extraction of IMI herbicides and determination using HPLC-UV is popular in literature, and it was used by many researchers because it provides clearer and more realistic results (Pace et al., 1999; Helling and Doherty, 1995; Laganà et al., 1998). Generally, herbicidal residues are usually concentrated in the top of $10 \mathrm{~cm}$, although it could leach deeper. These residues are injurious to non-tolerant rotational crops, such as wheat and corn (Alister and Kogan, 2005). Areas such as Tanjung Karang sees intensive use of IMI herbicides by farmers. The rice farmers have been applying IMI herbicides for $\sim 6$ years. We present a simple HPLC method that can be used to detect, analyze, and evaluate the residues of the imazapic and imazapyr in soils 
cultivated in Clearfield system. Reversed - phase liquid chromatography (RP-LC) with ultraviolet (UV) detection is widely used because it can separate high or medium polarity pesticides and detect them at low levels, making it one of the most powerful technique in separation methods (Hogendoorn, 2006). The farmers in this area have been applying IMI herbicides repeatedly (Mazlan et al., 2016). Therefore, this study was undertaken in the Clearfield fields to determine residues of IMI in the soil.

\section{Material and methods}

\section{Study site description}

Sawah Sempadan-Tanjung Karang district is located on (N 3'25'35.0724”, E 101'10'36.1704") in Kuala Selangor, Malaysia as shown in (Fig. 1). The soils samples were collected on November 2016/2017 from these fields, because the farmers there have been using IMI herbicides since its introduction in Malaysia in 2010 (Azmi et al., 2012). This area is the most prosperous agricultural district in Malaysia, and has many hectares of paddy rice (Mazlan et al., 2016).To determine the final IMI residue, the soil samples were collected at harvest time, which was $~ 90$ days after IMI was sprayed on Clearfield rice crop.

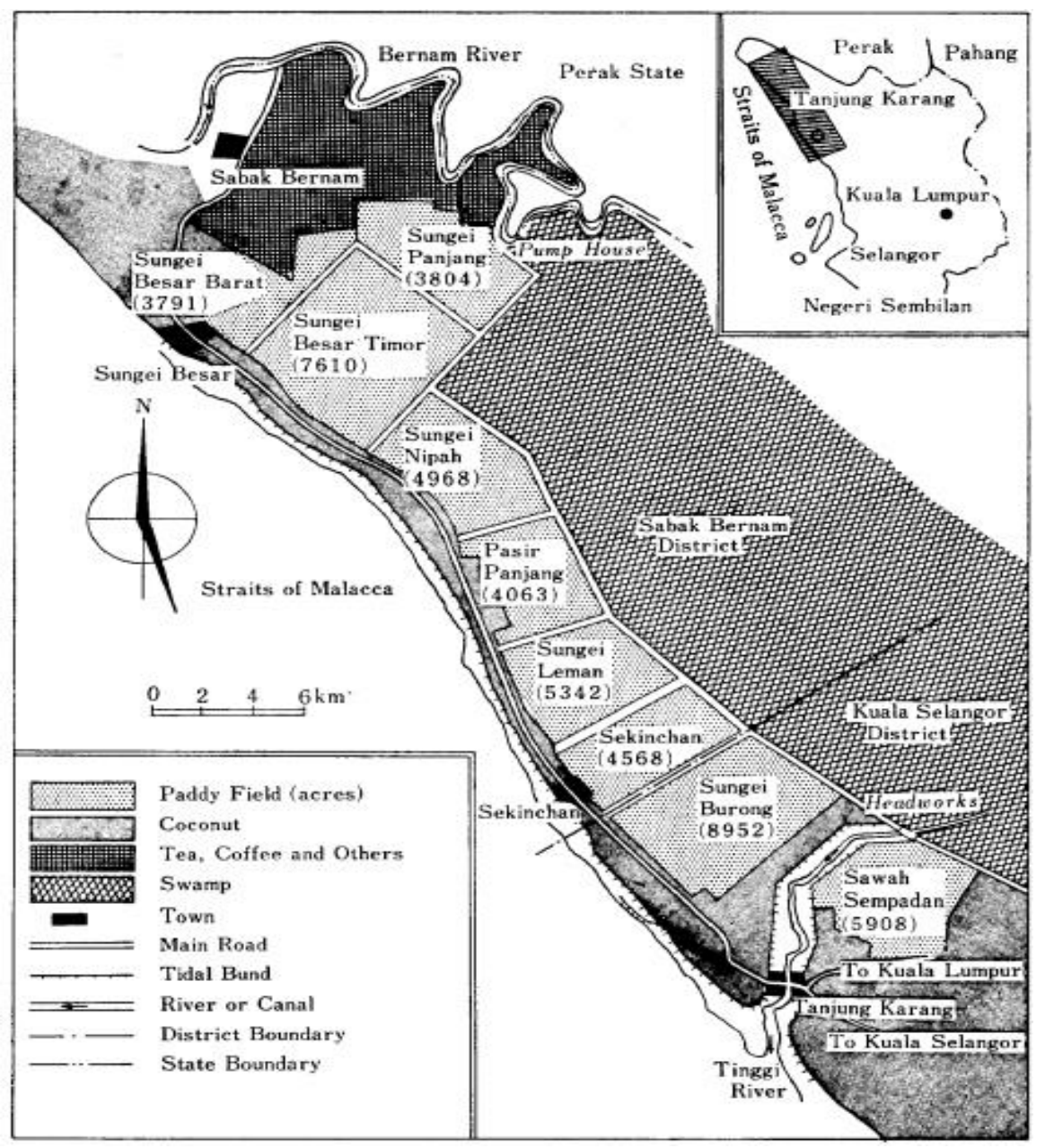

Figure 1. The site of soils sample from Sawah Sempadan-Tanjung Karang district(Fredericks, 1981) 


\section{Chemicals, reagents, and apparatus}

Standards of imazapyr (99.5\% purity) and imazapic (99.9\% purity) were purchased from Sigma-Aldrich (USA), while formic acid (85\%), methanol $99.9 \%$ (HPLC grade) and acetonitrile $99.9 \%$ (HPLC grade), acetic acid-ACS reagent (Fisher), formic acid98\% (EM Science), Sodium phosphate (Fisher), hydrochloric acid 6N (Fisher), phosphorous acid dichloromethane (DCM) $99.9 \%$ (HPLC grade), and Rotary evaporator were purchased from Sigma Aldrich (Germany). Ultrapure water was obtained from a Milli-Q Direct UV3® system (Millipore, USA), and was further purified by passing it through a $0.2 \mu \mathrm{m}$ Whatman filter paper. The HPLC 1100 series fitted with a UV detector was used. The HPLC column used in this work was a Zorbax $\mathrm{RX}-\mathrm{C}_{18}(4.6 \times 250 \mathrm{~mm}, 5 \mu \mathrm{m})$. Its temperature was maintained at $30{ }^{\circ} \mathrm{C}$. CentrifugeDupont Sorvall Model RC-5C, centrifuge bottles with cap $45 \mathrm{ml}$ polypropylene (Kontes Scientific), vortex mixer (Labmart 3000), Thermo-ultra-sonic, analytical balances (AUW-220D and UX-420H from Shimadzu, Japan), $0.22 \mu \mathrm{m}$ nylon filters, glass vials with capacity of $2 \mathrm{~mL}$ (Agilent, USA), and screw-capped polypropylene tubes $(45 \mathrm{ml}$, Germany), DSC-18 $6 \mathrm{ml}$ tubes $500 \mathrm{mg}(6 \mathrm{~cm} \times 3 \mathrm{~cm})$ SPE cartridges (supelco), anhydrous sodium sulfate, and a vacuum pump were all used in this work as well.

\section{Stock solution and working standards preparation}

Standards stock solutions of the herbicides imazapyr and imazapic were individually prepared in methanol at concentrations of $(100 \mu \mathrm{g} / \mathrm{ml})$, respectively, from $(1000 \mu \mathrm{g} / \mathrm{ml})$. Different fresh diluted solutions were prepared as $0.1,0.5,1,5,10$, and $20 \mu \mathrm{g} / \mathrm{ml}$, and diluted in methanol. All stock and working solutions were stored at $-18{ }^{\circ} \mathrm{C}$ in the dark (Marcia, 2014). Then, each of these solutions was injected $(17 \mu \mathrm{L})$ into the HPLC system, at $251 \mathrm{~nm}$, and peak areas were recorded and plotted versus the concentration of the herbicides.

\section{Soil collection and preparation}

The sample preparation process which involves extracting the analyte is very important and crucial. To determine the herbicidal residues from the soil samples, the samples were taken systemically from a randomly chosen area from three Clearfield ${ }^{\circledR}$ rice fields that were exposed to the herbicides. The basic approach is to analyze the depth intervals of the soils samples for each field. Each sample was within $0-20 \mathrm{~cm}$ and $20-40 \mathrm{~cm}$, about 30-m distance between each two samples was taken with the helical shape method. A 20 soil samples were taken, and 500-gram (gm) soil samples were collected using special auger for collection of the soil samples for increased control, and were stored in sterile zip lock polyethylene bags and coded with special code water proof stickers.

Three random samples were selected (two from each field), then one sample was selected randomly for examination, while the rest were stored in a refrigerator at a suitable temperature for subsequent analyses. The samples were air-dried in the special room at $35 \mathrm{C}^{\circ}$ for up to 5 days, grounded with a mortar and electronic machine, sieved through stainless steel sieve $(2.0 \mathrm{~mm})$ and stored at $4{ }^{\circ} \mathrm{C}$. A100 $\mathrm{g}$ of homogenized soil samples was stored in polyethylene bag at a temperature of $\sim 15 \mathrm{C}^{\circ}$ until it was analyzed for herbicidal residues. The soil physico-chemical characteristics were analyzed and the basic properties of these soils are shown in (Table 1). 
Table 1. soil texture characteristics of three locations soil

\begin{tabular}{lcccccccc}
\hline Location & Depth $(\mathbf{c m})$ & PH & Moisture\% & Sand\% & Silt\% & Clay\% & OM\% & Soil type \\
\hline \multirow{2}{*}{ Field A } & $0-20$ & 6.21 & 38 & 39 & 29 & 30 & 2 & Clay loamy \\
& $20-40$ & 6.7 & 33 & & & & & \\
\multirow{2}{*}{ Field B } & $0-20$ & 6.81 & 44 & 24.6 & 35.7 & 39.2 & 1.3 & Clay loamy \\
& $20-40$ & 6.61 & 57 & & & & & \\
\multirow{2}{*}{ Field C } & $0-20$ & 7.1 & 38 & 25 & 35 & 38 & 1.9 & Clay loamy \\
& $20-40$ & 6.94 & 59 & & & & & \\
\hline
\end{tabular}

\section{Soil extraction procedure for IMI Residue level}

Analyses of the samples of soil were carried out using the modified extracted published methods proposed by (Ramezani et al., 2009; Krynitsky et al., 1999). About 5 $\pm 0.001 \mathrm{~g}$ of a randomly homogenized soil sample was weighted, which provides appropriate and representative amount as some authors have used (Martins et al., 2014). The portion soil was placed in $250 \mathrm{ml}$ centrifuge tube (polypropylene), $150 \mathrm{ml}$ of extracted $0.5 \mathrm{~N} \mathrm{NaOH}$. Then sample was kept 45 minutes in an end-over-end shaker at $30^{\circ} \mathrm{C}$ to assess the homogeneity of the sample. A $10 \mathrm{ml}$ methanol was added to precipitate humic acids and sonicated for 10 minutes, then centrifuge the sample for 10 minutes at $7000 \mathrm{rpm}$ to remove particulates.

The sample solution was filtered and adjusted to $\mathrm{pH} 2$ by addition of $6 \mathrm{~N}$ hydrochloric acid. Clean-up is necessary to shift down the detection limits of methods and to avoid interferences from the matrix. The suspension was left at room temperature for 10 minutes until analysis, then transferred into a $500 \mathrm{ml}$ separatory funnel and extracted with two $50 \mathrm{ml}$ portions of dichloromethane (DCM). The extracts were combined and the DCM was dried using anhydrous $\mathrm{Na}_{2} \mathrm{SO}_{4}$, then passed through smooth activated charcoal. The resulting solution was then transferred into a 250-ml round bottom flask and solvent was evaporated at $65{ }^{\circ} \mathrm{C}$ using a rotary evaporator at a low speed to near dryness. The residue was diluted with about $2 \mathrm{ml}$ of a 1:1 solution of methanol:0.1\% formic acid, then loaded (under vacuum) into the $6 \mathrm{ml}$ DSC-18 (Supelco) solid phase extraction cartridge containing $500 \mathrm{mg}$ of polymeric of adsorbing material conditioned with $3 \mathrm{ml}$ of each of the solvents methanol, acetonitrile, and $\mathrm{H}_{2} \mathrm{O}$.

The vacuum was slowly reduced and the analytes were washed with $9 \mathrm{ml} \mathrm{H}_{2} \mathrm{O}$ and 6 $\mathrm{ml}(60: 40)\left(\mathrm{H}_{2} \mathrm{O}\right.$ : acetonitrile). Finally, the vials were placed in the vacuum apparatus and the cartridge eluted with $3 \mathrm{ml}$ of the methanol:0.1\% formic acid solution. The resulting extract was filtered through a $0.22 \mu \mathrm{m}$ polytetrafluoroethylene (PTFE) membrane, transferred to a $1.5 \mathrm{ml}$ HPLC auto sampler vial, and stored at $4^{\circ} \mathrm{C}$ until separation by HPLC.

\section{Method application}

In this study, 20 samples were taken from the same three sites of Sawah SempadanTanjung Karang district, and different chemical compositions and $\mathrm{pH}$ values were analyzed. 


\section{Accuracy (\%Recovery), limit of detection (LOD), and limit of Quantitation (LOQ)}

LOD is the lowest concentration that can be detected, and it could be determined by a statistical method. This could be achieved by measuring the more dilute concentrations of analyte. These concentrations are expected to produce a response of $\sim 3$ times the background noise. LOD should be between $3-10$. The LOQ is expected to behave similarly, but with a ratio of 10 times the background noise. Recovery studies in soils samples were conducted using the standard calibration curves equation.

These herbicides were spiked to blank soils (clean soils free from herbicides), taken from the land around University Malaya (N 37’8.9328' E101³9'28.494”). This soil was selected due to its similar characteristics with the tested soil samples. Acetone was added to $5 \mathrm{~g}$ of dried homogenized soil at different concentrations, and left to dry for $48 \mathrm{~h}$ at room temperature to activate the introgression and equilibrium while slowly evaporating the solvent (Rebelo et al., 2016; Laganà et al., 2000), followed by extraction and analysis using HPLC-UV.

\section{Results and discussion}

Contamination of environmental resources by herbicides is an increasing environmental concern. Undoubtedly, soil plays a significant role in an agro-ecosystem, but information for analysis of these types of herbicide residues in the soil can be very difficult to achieve. HPLC with UV detection was chosen due to it being a fast and effective separation method. This study involves trying different columns and mobile phases for the HPLC technique. Finally, in this method a proper separation was achieved using the gradient mobile phase and $\mathrm{C}_{18}$ column $(4.6 \times 250 \mathrm{~mm}, 5 \mu \mathrm{m})$ was used for stationary phase separation.

Purified water was used as one of the mobile phases, due to its low cost, lack of toxicity to the environment (Laganà et al., 2000). The mobile phase acetonitrile (100\%), as one of mobile phase, is the best mobile phase (Martins et al., 2014; Demoliner et al., 2010), along with purified water acidified with $10 \%$ acetic acid ( $\mathrm{pH}$ to 2.8 ), due to the $\mathrm{pH}$ 's effect on the peak shape (Singh, 2013).

Therefore, acetonitrile was chosen due to it is great solubility and higher elution strength than dichloromethane for fractionating the analytes. Acetonitrile is the best choice for the mobile phase (Singh, 2013). However, analysis was carried out using gradient solvent program using mobile phase A (acetonitrile (100\%)) and mobile B (purified water acidified with $10 \%$ acetic acid ( $\mathrm{pH}$ adjusted to 2.8). The initial gradient program was $35 \%$ A, maintained for a minute, then increased to $45 \%$ for $3 \mathrm{~min}$, then decreased to $35 \%$ at 8 mins. The column temperature was set to $30 \mathrm{C}^{\circ}$. The flow rate was $1 \mathrm{ml} / \mathrm{min}$, injection volume was set to $17 \mu \mathrm{L}$, and UV detection was set to a wavelength of $251 \mathrm{~nm}$.

Simultaneously, methanol was evaporated before the sample is injected into the HPLC apparatus. Standard curve linearity and calibration was determined at six concentrations $(0.1$, $0.5,1,5,10$, and $20 \mu \mathrm{g} / \mathrm{ml}$ ), and were prepared in the laboratory by diluting the stock solution and plotting the analytes' concentration against peak area. Each level of the concentration was analyzed repeatedly. The equation of analytical calibration was obtained by plotting the peak areas on y-axis and the concentration on the x-axis within the previous calibration levels for both imazapic and imazapyr. The concentration of both herbicides was calculated by comparing the peak values in the calibration, using the regression equation. The linearity of the method was determined from the correlation coefficient, as per Fig. 2.

The matrix effect has been mentioned in literature and is explained via multiple perspectives, with some reporting a shift of over $10 \%$ on the analytical results (Kemmerich et 
al., 2015). However, some that are less than $20 \%$ does not affect the matrix (Ferrer et al., 2011). The chemical analysis of these herbicides in soil are often problematic due to the low detection limits required and the $\mathrm{pH}$ adjustment during the extraction process. IMI is a weak acid, as per (Table 2), therefore their presence in soil is influenced by $\mathrm{pH}$ (Schreiber et al., 2017). Soil particles were fine-grinded to increase the interaction between the solvents and soil particles, which lead to increased herbicides extraction.

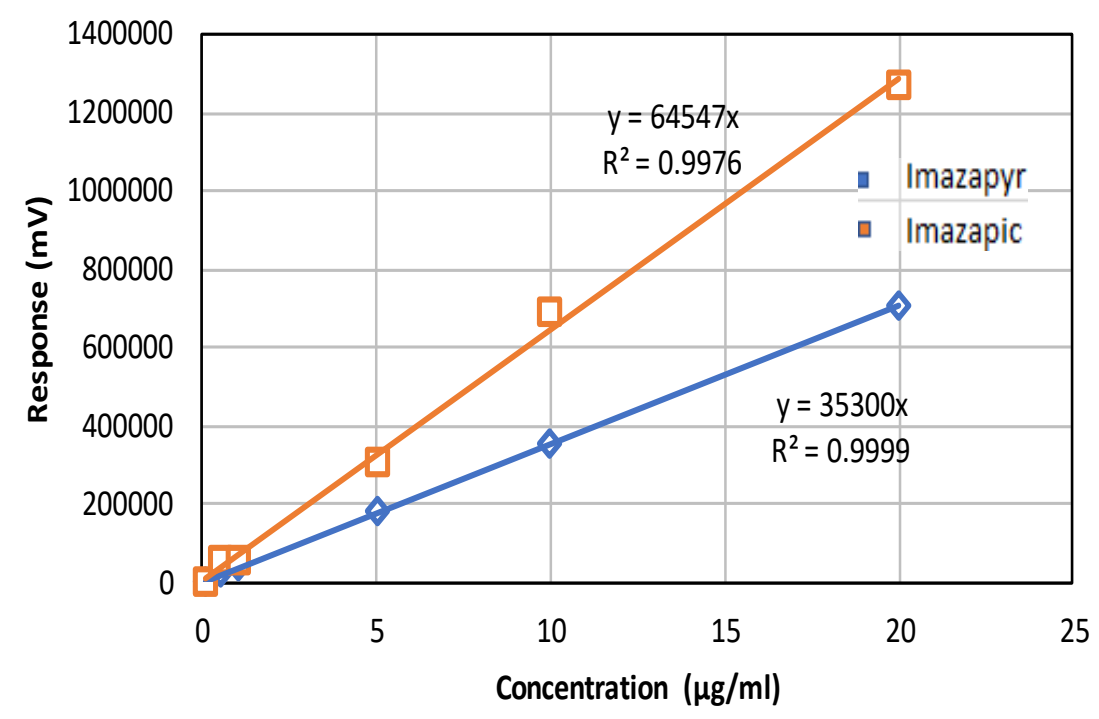

Figure 2. Representative calibration curve for IMI was obtained by the determination of six levels in duplicate at ranged from $0.1-20 \mu \mathrm{g} / \mathrm{ml}$

Table 2. The characteristics (Molecular and physicochemical) of imazapic and imazapyr

\begin{tabular}{|c|c|c|}
\hline Name & ${ }^{\mathrm{a}}$ Imazapic & ${ }^{\mathrm{a}}$ Imazapyr \\
\hline $\begin{array}{l}\text { Family/chemical } \\
\text { class }\end{array}$ & Imidazolinone & Imidazolinone \\
\hline Trade name & Cadre, panoramic, plateou & $\begin{array}{l}\text { Arsenal, Chopper, Habitat, } \\
\text { Stalker }\end{array}$ \\
\hline Chemical name & $\begin{array}{l}\text { [2-(4,5dihydro-4-methy-4-(1- } \\
\text { methylethyl)-5-oxo-1Himidazol-2-yl) } \\
\text { 5-methyl-3-pyridinecarboxylic acid] }\end{array}$ & $\begin{array}{l}\text { [2-(4-isopropyl- 4- methyl-5- } \\
\text { oxo-2-imidazoline-2-yl) } \\
\text { nicotinic acid] }\end{array}$ \\
\hline Molecular weight & $275.30308 \mathrm{~g} / \mathrm{mol}$ & $261.2765 \mathrm{~g} / \mathrm{mol}$ \\
\hline Molecular formula & $\mathrm{C}_{14} \mathrm{H}_{17} \mathrm{~N}_{3} \mathrm{O}_{3}$ & $\mathrm{CO}_{13} \mathrm{H}_{15} \mathrm{~N}_{3} \mathrm{O}_{3}$ \\
\hline \multicolumn{3}{|l|}{ Structural formula } \\
\hline Water solubility & $2200 \mathrm{mg} / \mathrm{L}$ & $9740 \mathrm{mg} / \mathrm{L}$ \\
\hline Life time in soil & Around 120days & 90-120 days \\
\hline${ }^{\mathrm{b}} \mathrm{pKa}$ & $2.1,3.9$ & $1.9,3.6$ \\
\hline${ }^{\mathrm{c}}$ Goss & High potential & High potential \\
\hline
\end{tabular}

${ }^{a}$ Data quoted from (Senseman, 2007, Schreiber et al., 2017).

${ }^{\mathrm{b}}$ Indicates the $\mathrm{pH}$ value at which $50 \%$ of total molecules are associated in soil and $50 \%$ of total molecules are dissociated.

${ }^{\mathrm{c}}$ Method of classification of potential surface water contamination. 
The traditional types of extractions ordinarily use the chemical compound PSA (primary secondary amine), and due to the fact that the IMI family are present in multiple forms, it acts as a weak acid/base, which allows PSA to hold over acidic herbicides (Marcia, 2014). One of the important effects occurs when the types of herbicides have $\mathrm{pK}_{\mathrm{a}}$ values in the range 1.3-3.9 (Krieger, 2001), which includes the weak acid IMI herbicides. Based on this, the shape of the peak area during analysis was expected to be affected by the value of the $\mathrm{pH}$ of the mobile phase. Soil $\mathrm{pH}$ and the microbial activity are the main factors in the degradation process of IMI herbicides in the soil (Sondhia et al., 2015). For example, when the $\mathrm{pH}$ increases, the adsorption and persistence decreases.

Also, another important factor that control the residues' concentration is the depth and type of soil. IMI sorption is correlated and increased with clay content, due to increased binding of the herbicide to soil particles, where (Gianelli et al., 2014). (Burnside et al., 1963) show that some herbicides can leach deep into the soil. For example, some studies revealed that the sorption of these types of IMI as imazapyr to sandy soils is very weak compared to its sorption to clay and humic soils (Lode and Meyer, 1999). The agricultural soils contain numerous impurities and old chemicals, which can persist for a long time, which would cause separation problems in the column, especially if the soil contained only very low concentrations of imazapic or imazapyr. Imazapyr and imazapic have the potential to leach into groundwater due to its persistence and mobility in soils, and very low volatility (Gianelli et al., 2014). Certified imazapic and imazapyr (USA) were used for calibration (Fig. 3 and Fig. 4).

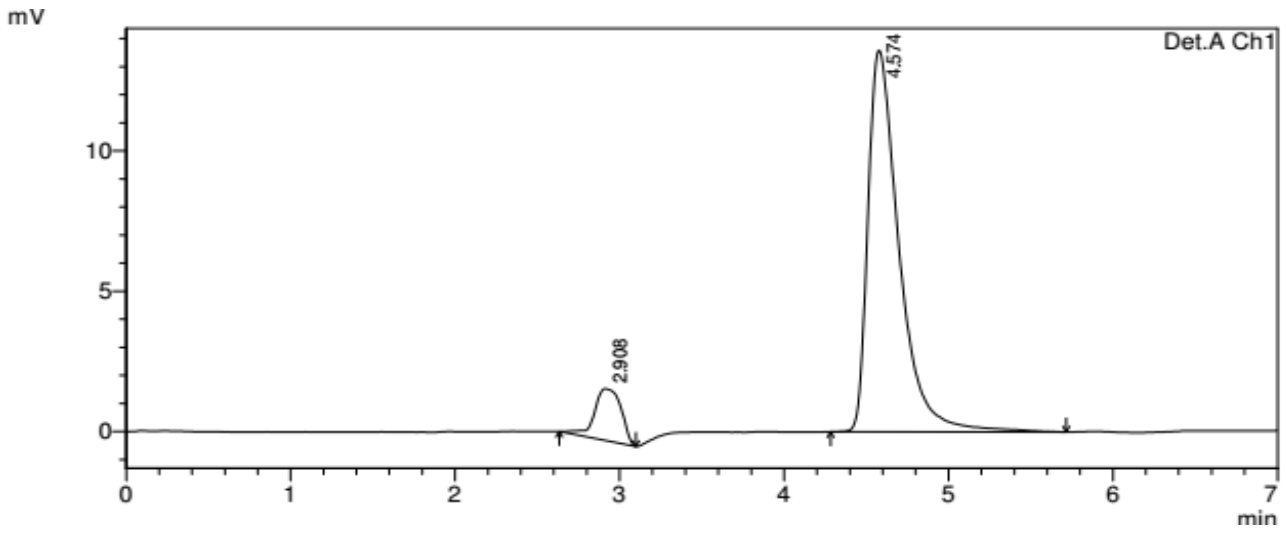

Figure 3. Imazapyr standard, 10ppm

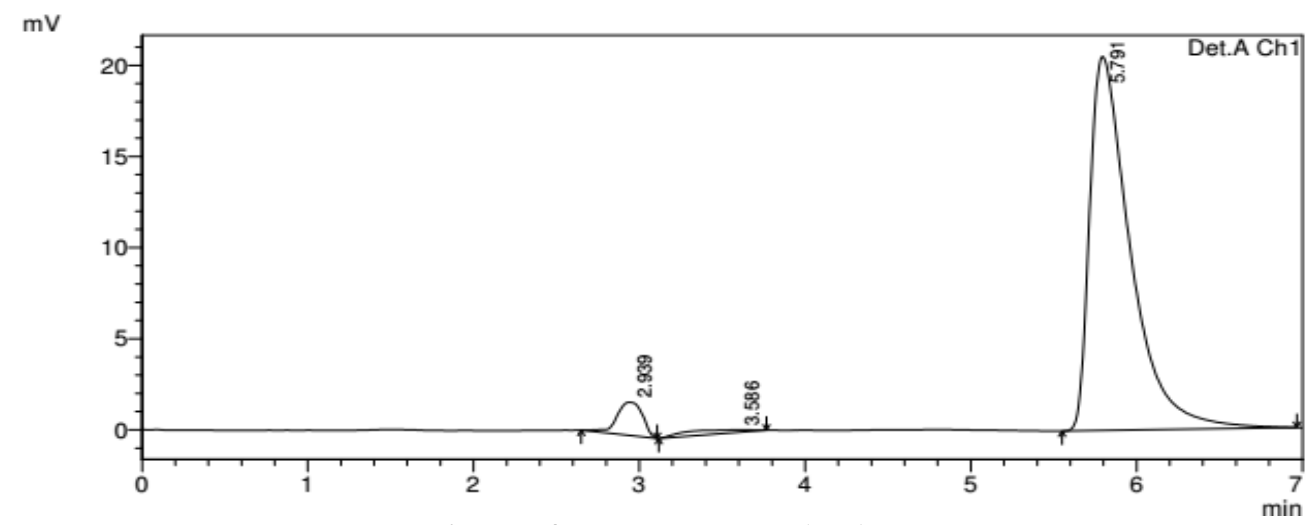

Figure 4. Imazapic standard, 10ppm 
The adsorption of IMI herbicides decreases by increasing heavy rain and temperatures. The higher solubility of these types in water, high temperatures, and great rainfall in Malaysia are main factors that play important roles in the transition of residual particles of herbicides via its pores or movement to other places and shift up the degradation mechanism, as per (Grey et al., 2012; Fish et al., 2015). Malaysia has almost daily high intensity rain fall and temperatures. Studies revealed that temperatures between $35 \mathrm{C}^{\circ}-45 \mathrm{C}^{\circ}$ and increased soil moisture enhance both the chemical and microbial degradation for herbicides (Neto et al., 2017). Different methods are applicable for extraction of IMI herbicides from soil samples, but most are not satisfactory (de Oliveira Arias et al., 2014). Despite the fact that imazapyr and imazapic were applied in low doses, both can remain for long periods of time in the soil, which can cause agronomic and environmental problems (Kraemer et al., 2009). However, leaching is influenced by the environment, which means that when the water content decrease from the upper surface, it leads to increased $\mathrm{pH}$. Also, some chemical herbicides move to the upper surface of the soil due to capillary action, which causes it to evaporate (Mangels, 1991).

\section{Selectivity}

Selectivity is defined as the evaluation or detection of the analyte from others analytes and different compounds that could be present at the same moment in the matrix or the sample (Ahuja, 1989). There were no matrix peaks in the chromatogram analysis that interfere with analysis of the residues as shown in Fig. 5 and Fig. 6.

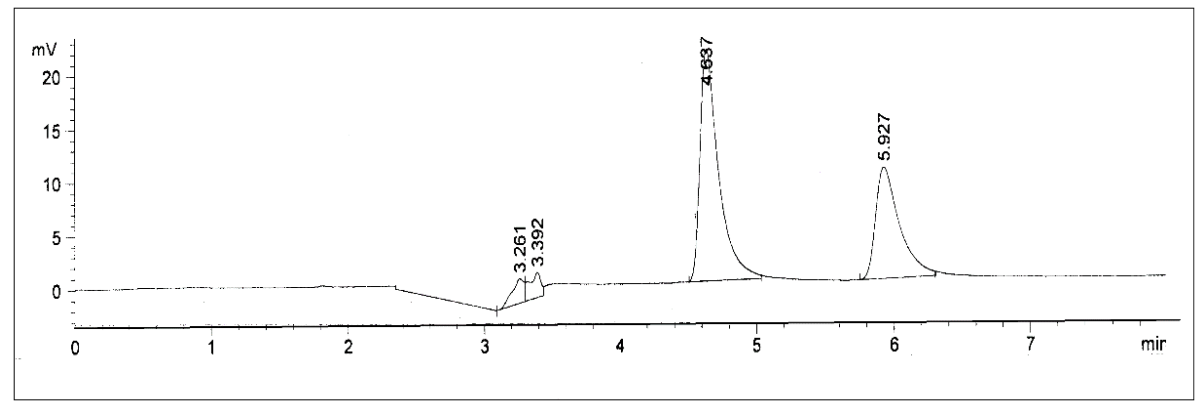

Figure 5. Extraction imazapic and imazapyr with good resolution

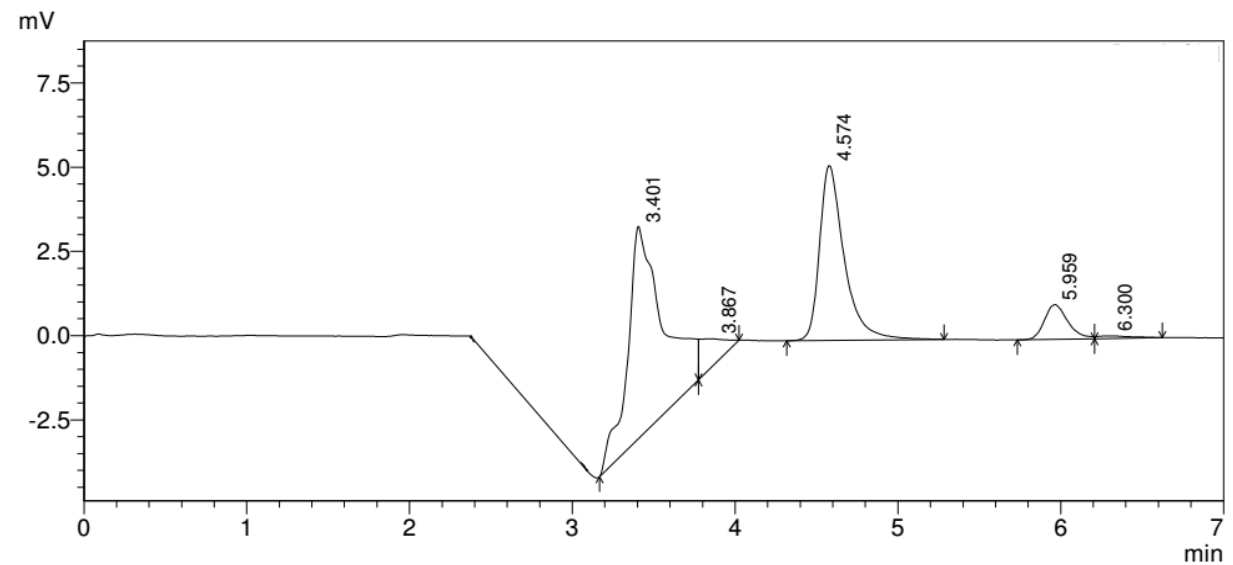

Figure 6. Extraction imazapic and imazapyr with good resolution 


\section{Accuracy (\%Recovery)-Limit of detection (LOD) and limit of Quantitation (LOQ)}

The achieved results revealed an excellent linearity at different concentrations of imazapyr and imazapic standards in the range from 0.1 to $5 \mu \mathrm{g} / \mathrm{mL}$. These herbicides' concentrations are spiked to blank soils as described in the experimental section.

Due to the spiking of the extracts, the final comparison between the two systems is expected to be valid. The precision and recovery for the two herbicides was calculated through the injection of freshly prepared six standards. The proportion of the area of the peak of herbicide resulting from the spiked solution to the area of the herbicide peak resulting from a standard solution prepared previously was calculated. The average percentage recoveries for imazapyr and for imazapic varied from 76\%-107\% and 71$79 \%$ with $0.1-5 \mu \mathrm{g} / \mathrm{ml}$ fortification level, and $0.1-10 \mu \mathrm{g} / \mathrm{ml}$ at fortification level, respectively, are shown in (Table 3). The LOD and LOQ were found to be 1.04 and $3.15 \mu \mathrm{g} / \mathrm{ml}$ for imazapic, and 0.135 and $0.411 \mu \mathrm{g} / \mathrm{ml}$ for imazapyr, respectively, in the top $15 \mathrm{~cm}$. In the extracted soil sample, it was $0.19 \mu \mathrm{g} / \mathrm{ml}$ for imazapic and $0.04 \mu \mathrm{g} / \mathrm{ml}$ for imazapyr. This proves the slow degradation process of these residues in the soils under environmental conditions. The soil samples were taken during rice crop cultivation of about 90 days and the residues are evidently still present.

The Koc for the two herbicides were 137 and $100 \mathrm{ml} \mathrm{g}^{-1}$, respectively, which means low adsorption and high mobility, and eventually high levels of leaching. Nevertheless, both herbicide residues are still present after $~ 90$ days, especially imazapic with 0.2 $\mu \mathrm{g} / \mathrm{ml}$, which was proven by a previous study stating that these types of herbicides are highly persistent (Souza et al., 2016). Simultaneously, persistence of residues in the soil does not necessarily mean that it injures sensitive crops, as persistence differs from bioavailability.

Table 3. Recovery of imazapic from soil

\begin{tabular}{ccccc}
\hline $\begin{array}{c}\text { Con. } \\
(\mu \mathrm{g} / \mathrm{ml})\end{array}$ & $\begin{array}{c}\text { Recovered } \\
\text { peak } \\
\text { imazapic }\end{array}$ & $\begin{array}{c}\text { Recovered } \\
\text { peak } \\
\text { imazapyr }\end{array}$ & $\begin{array}{c}\text { Average } \\
\% \\
\text { imazapic }\end{array}$ & $\begin{array}{c}\text { Recovery } \\
\% \\
\text { imazapyr }\end{array}$ \\
\hline 0.1 & 2475 & 3943.66 & 71.18 & 107.165 \\
0.5 & 43513 & 17263.6 & 79.19 & 80.74 \\
5 & 236358 & 137529.6 & 77.27 & 76.768 \\
10 & 521185 & 341438.3 & 75.75 & 96.253 \\
\hline
\end{tabular}

\section{Repeatability and stability}

The repeatability of this method was determined by calculating the RSD of the peak areas of the six duplicate injections of fortified samples which is $<15$. It represents the closeness of the results from similar methods, laboratories, and tools. This is achieved via six concentrations, each replicated trice to a total of eighteen times, encompassing the specified range of the procedure. Accuracy $=$ mean $\pm \mathrm{SD}$, for imazapic $75.85 \pm 3.4$, and for imazapyr, it was $90.232 \pm 14$.

\section{Conclusions}

A simple analytical method based on HPLC-UV was developed and validated to determine the IMI residues in the Clearfield ${ }^{\circledR}$ rice soils. It is necessary to monitor the 
presence of herbicides residues in soils and waters and develop methods for reliable analysis, as important tools of regulatory programs to protect the environment. A gradient of mobile phase A (acetonitrile (100\%)) and mobile B (purified water acidified with $10 \%$ acetic acid ( $\mathrm{pH}$ adjusted to 2.8 )) yields excellent separation and resolution, in a short analysis time, for the two herbicides (less than $7 \mathrm{~min}$ ), with retention time for imazapyr and imazapic at $\sim 4.6$ and 5.9 min respectively. Excellent linearity in the range of injected standard concentrations with a high degree of precision and accuracy could be achieved. Therefore, the proposed analytical method could be useful for detecting the imidazolinone family in agricultural soil and water in the future. Results of this study suggests the need for an extensive research to determine factors affecting the half-life of these herbicides and their contribution to their persistence. Also, further studies are needed on the laboratory level and plant bioassay to evaluate if these residues can indeed cause injuries to other crops.

Acknowledgements. The authors would like to thank the Fundamental Research Grant Scheme, FRGS: FP001-2015A and the University Malaya Research Grant, UMRG: RG 311-14AFR.

\section{REFERENCES}

[1] Ahuja, S. (1989): Selectivity and detectability optimizations in HPLC. - John Wiley \& Sons.

[2] Alister, C., Kogan, M. (2005): Efficacy of imidazolinone herbicides applied to imidazolinone-resistant maize and their carryover effect on rotational crops. - Crop Protection 24: 375-379.

[3] Anastassiades, M., Lehotay, S. J., Stajnbaher, D., Schenck, F. J. (2003): Fast and easy multiresidue method employing acetonitrile extraction/partitioning and "dispersive solidphase extraction" for the determination of pesticide residues in produce. - Journal of AOAC INTERNATIONAL 86: 412-431.

[4] Andreu, V., Picó, Y. (2004): Determination of pesticides and their degradation products in soil: critical review and comparison of methods. - Trends in Analytical Chemistry 23: 772-789.

[5] Assalin, M. R., Queiroz, S. C., Ferracini,V L., Oliveira, T., Vilhena, E., Mattos, M. L. T. (2014): A method for determination of imazapic and imazethapyr residues in soil using an ultrasonic assisted extraction and lc-ms/ms. - Bulletin of Environmental Contamination and Toxicology 93: 360-364.

[6] Azmi, M., Azlan, S., Yim, K., George, T., Chew, S. (2012): Control of weedy rice in direct-seeded rice using the clearfield production system in malaysia. - Pak. J. Weed Sci. Res. 18: 49-53.

[7] Bailey, W.A., Wilcut, J. W. (2003): Tolerance of imidazolinone-resistant corn (zea mays) to diclosulam 1. - Weed Technology 17: 60-64.

[8] Bajrai, F. S. M., Ismail, B. S., Mardiana-Jansar, K., Omar, R. (2017): Persistence of imazapic and imazapyr in paddy soil and water.- Int'l Journal of Advances \& Environmental Engg. 4(1): 12-15.

[9] Baki, B., Shakirin, M. (2010): Spatio-temporal distribution pattern of new biotypes of weedy rice (oryza sativa 1.) in selangor north-west project, malaysia. - Korean Journal of Weed Science 30: 68-83.

[10] Börjesson, E., Torstensson, L., Stenström, J. (2004): The fate of imazapyr in a swedish railway embankment. - Pest Management Science 60: 544-549.

[11] Burgos, N. R., Singh, V., Tseng,T. M., Black, H., Young, N. D., Huang, Z., Hyma, K. E., Gealy, D. R., Caicedo, A. L. (2014): The impact of herbicide-resistant rice technology on 
phenotypic diversity and population structure of united states weedy rice. - Plant Physiology 166: 1208-1220.

[12] Burnside, O., Fenster, C., Wicks, G. (1963): Dissipation and leaching of monuron, simazine, and atrazine in nebraska soils. - Weeds 209-213.

[13] De Oliveira Arias, J. L., Rombaldi, C., Caldas, S. S., Primel, E. G. (2014): Alternative sorbents for the dispersive solid-phase extraction step in quick, easy, cheap, effective, rugged and safe method for extraction of pesticides from rice paddy soils with determination by liquid chromatography tandem mass spectrometry. - Journal of Chromatography A 1360: 66-75.

[14] Demoliner, A., Caldas, S. S., Costa, F. P., Gonçalves, F. F., Clementin, R. M., Milani, M. R., Primel, E. G. (2010): Development and validation of a method using spe and lc-esi$\mathrm{ms}-\mathrm{ms}$ for the determination of multiple classes of pesticides and metabolites in water samples. - Journal of the Brazilian Chemical Society 21: 1424-1433.

[15] Ferrer, C., Lozano, A., Agüera, A., Girón, A. J., Fernández-Alba, A. (2011): Overcoming matrix effects using the dilution approach in multiresidue methods for fruits and vegetables. - Journal of Chromatography A 1218: 7634-7639.

[16] Fish, J. C., Webster, E. P., Blouin, D. C, Bond, J. A. (2015): Imazethapyr co-application interactions in imidazolinone-resistant rice. - Weed Technology 29: 689-696.

[17] Fredericks, L. (1981): Ecology, new technology and rural development: impressions of Kampung Ulu Tiram Burok (special issue) green revolution and rural development in Asia).- Southeast Asian Studies 18(4): 587-605.

[18] Gianelli, V. R., Bedmar, F., Costa, J. L. (2014): Persistence and sorption of imazapyr in three argentinean soils. - Environmental Toxicology and Chemistry 33: 29-34.

[19] Grey, T. L., Cutts III, G. S., Johnson, J. (2012): Imidazolinone-resistant soft red winter wheat weed control and crop response to ALS-inhibiting herbicides. - Weed Technology 26: 405-409.

[20] Helling, C. S. \& Doherty, M. A. 1995. Improved method for the analysis of imazapyr in soil. pesticide science, 45, 21-26.

[21] Hogendoorn, E. A. (2006): High-performance liquid chromatography methods in pesticide residue analysis. - Encyclopedia of Analytical Chemistry, DOI: 10.1002/9780470027318.a1712

[22] Kemmerich, M., Bernardi, G., Adaime, M. B., Zanella, R., Prestes, O. D. (2015): A simple and efficient method for imidazolinone herbicides determination in soil by ultrahigh performance liquid chromatography-tandem mass spectrometry. - Journal of Chromatography A 1412: 82-89.

[23] Krieger, R. (2001): Handbook of pesticide toxicology, two-volume set: principles and agents. - Academic Press.

[24] Krynitsky, A. J., Stout, S. J., Nejad, H., Cavalier, T. C. (1999): Multiresidue determination and confirmation of imidazolinone herbicides in soil by high-performance liquid chromatography/electrospray ionization mass spectrometry. - Journal of AOAC INTERNATIONAL 82: 956-962.

[25] Laganà, A., Fago, G., Marino, A. (1998): Simultaneous determination of imidazolinone herbicides from soil and natural waters using soil column extraction and off-line solidphase extraction followed by liquid chromatography with UV detection or liquid chromatography/electrospray mass spectroscopy. - Analytical Chemistry 70: 121-130.

[26] Laganà, A., Fago, G., Marino, A., Penazzi, V. M. (2000): Liquid chromatography mass spectrometry tandem for multiresidue determination of selected post-emergence herbicides after soil column extraction. - Analytica Chimica Acta 415: 41-56.

[27] Lode, O., Meyer, K. (1999): Report 'leaching of pesticides'. - The Norwegian Crop Research Institute 8: 99.

[28] Azmi, M., Azlan, S., Yim, K. M., Chew, S. E. (2011): Control of weedy rice in directseeded rice using the Clearfield production system in Malaysia. book, 1, 26-29. 
[29] Mangels, G. (1991): Behavior of the imidazolinone herbicides in soil-a review of the literature. The imidazolinone herbicides. - Boca raton, fl: crc, 191-209.

[30] Marcia, E. A. (2014): Amethod for determination of imazapic and imazethapyr residues in soil using an ultrasonic assisted extraction. - Bull. Environ. Contam. Toxical. 93: 360364.

[31] Martins, G. L., Friggi, C. A., Prestes, O. D., Vicari, M. C., Friggi, D.A., Adaime, M. B., Zanella, R. (2014): Simultaneous $1 \mathrm{c}-\mathrm{ms} / \mathrm{ms}$ determination of imidazolinone herbicides together with other multiclass pesticide residues in soil. - CLEAN-Soil, Air, Water 42: 1441-1449.

[32] Mazlan, A. Z., Hussain, H., Zawawi, M. A. M. (2016): Potential dermal exposure assessment of farmers to herbicide imazapic in an agriculture area. - Procedia-Social and Behavioral Sciences 234: 144-153.

[33] Michael, J. L., Neary, D. G. (1993): Herbicide dissipation studies in southern forest ecosystems. - Environmental Toxicology and Chemistry 12: 405-410.

[34] Neto, M. D. D. C., Souza, M. D. F., Silva, D. V., Faria, A.T., Da silva, A. A., Pereira, G. A. M., De freitas, M. A. M. (2017): Leaching of imidazolinones in soils under a clearfield system. - Archives of Agronomy and Soil Science 63: 897-906.

[35] Pace, P., Senseman, S., Ketchersid, M., Cralle, H. (1999): Supercritical fluid extraction and solid-phase extraction of ac 263,222 and imazethapyr from three texas soils. Archives of Environmental Contamination and Toxicology 37: 440-444.

[36] Ramezani, M., Simpson, N., Oliver, D., Kookana, R., Gill, G., Preston, C. (2009): Improved extraction and clean-up of imidazolinone herbicides from soil solutions using different solid-phase sorbents. - Journal of Chromatography A, 1216: 5092-5100.

[37] Rebelo, A. M., Dolzan, M. D., Heller, M., Deschamps, F. C., Abate, G., Micke, G. A., Grassi, M. T. (2016): Simultaneous determination of herbicides in rice by quechers and lc-ms/ms using matrix-matched calibration. - Journal of the Brazilian Chemical Society 27: 186-193.

[38] Schreiber, F., Scherner, A., Massey, J. H., Zanella, R., Avila, L. A. (2017): Dissipation of clomazone, imazapyr, and imazapic herbicides in paddy water under two rice flood management regimes. - Weed Technology 31: 330-340.

[39] Senseman, S. A. (2007): Herbicide handbook. - Lawrence, US: Weed Science Society of America.

[40] Silva, D. R. O. D., Avila, L. A. D., Agostinetto, D., Dal magro, T., Oliveira, E. D., Zanella, R., Noldin, J. A. (2009): Pesticides monitoring in surface water of rice production areas in southern brazil. - Ciência Rural 39: 2383-2389.

[41] Singh, R. (2013): HPLC method development and validation-an overview. - Journal of Pharmaceutical Education and Research 4: 26.

[42] Sondhia, S., Khankhane, P. J., Singh, P. K., Sharma, A. R. (2015): Determination of imazethapyr residues in soil and grains after its application to soybeans. - Journal of Pesticide Science, 40.

[43] Souza, M., C neto, M., Marinho, M., Saraiva, D., Faria, A., Silva, A., Silva, D. (2016): Persistence of imidazolinones in soils under a clearfield system of rice cultivation. Planta Daninha 34: 589-596.

[44] Watanabe, H., Man, A., Ismail, M. Z. (1996): Ecology of major weeds and their control in direct seeding rice culture of Malaysia. - Japan International Research Center for Agricultural Science, Malaysian Agricultural Research and Development Institute, Muda Agricultural Development Authority, 202 pp. 